
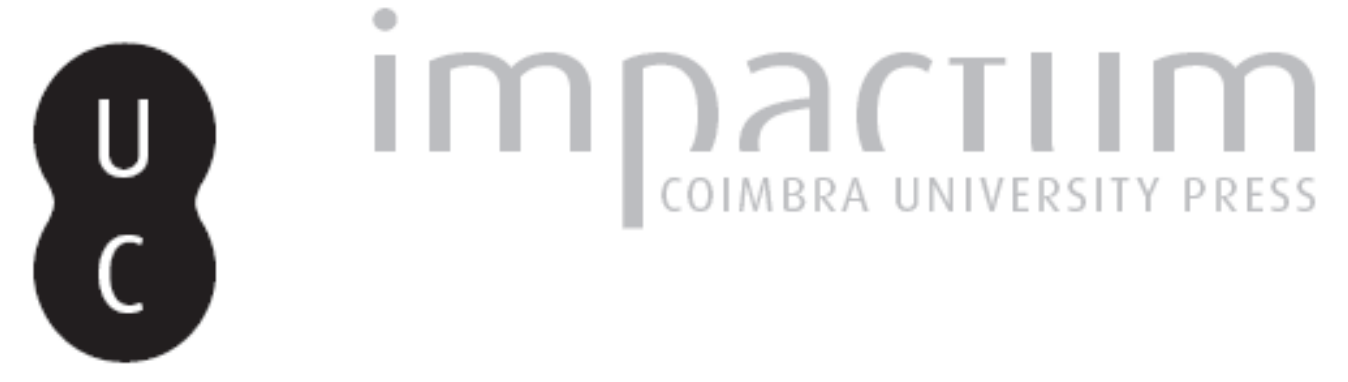

\title{
Minnette de Silva: a arquitecta do Sri Lanka
} \author{
Autor(es): $\quad$ Navarro, Joana; Monteiro, Paula; Monsanto, Sara; Antunes, Tânia;
}

Publicado por: Editorial do Departamento de Arquitectura

URL persistente:

URl:http://hdl.handle.net/10316.2/37211

DOI:

DOI:http://dx.doi.org/10.14195/1647-8681_1_10

Accessed : $\quad$ 26-Apr-2023 15:59:47

A navegação consulta e descarregamento dos títulos inseridos nas Bibliotecas Digitais UC Digitalis, UC Pombalina e UC Impactum, pressupõem a aceitação plena e sem reservas dos Termos e Condições de Uso destas Bibliotecas Digitais, disponíveis em https://digitalis.uc.pt/pt-pt/termos.

Conforme exposto nos referidos Termos e Condições de Uso, o descarregamento de títulos de acesso restrito requer uma licença válida de autorização devendo o utilizador aceder ao(s) documento(s) a partir de um endereço de IP da instituição detentora da supramencionada licença.

Ao utilizador é apenas permitido o descarregamento para uso pessoal, pelo que o emprego do(s) título(s) descarregado(s) para outro fim, designadamente comercial, carece de autorização do respetivo autor ou editor da obra.

Na medida em que todas as obras da UC Digitalis se encontram protegidas pelo Código do Direito de Autor e Direitos Conexos e demais legislação aplicável, toda a cópia, parcial ou total, deste documento, nos casos em que é legalmente admitida, deverá conter ou fazer-se acompanhar por este aviso.

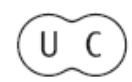




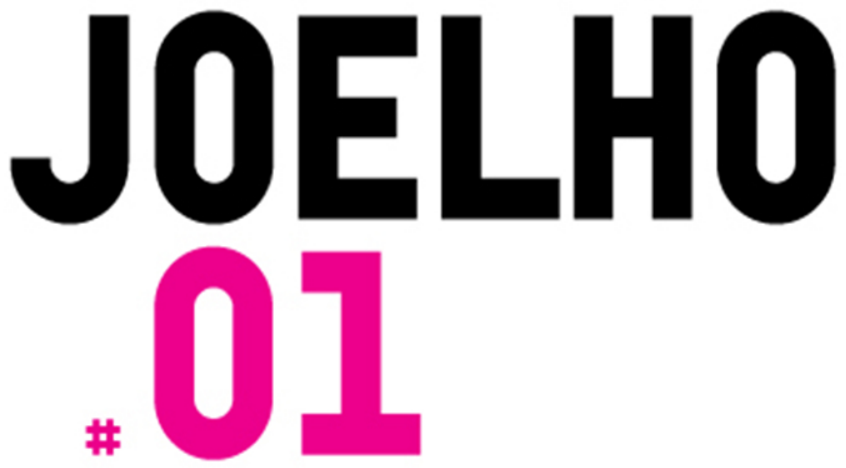

\section{MULHERES NA ARQUITECTURA}

Jorge Figueira

Coordenação

Silvana Rubino

Carla Lopes

Liliana Carvalho

Joana Bem-Haja

Filipa Cabrita

Inês Antunes

Telma Silva

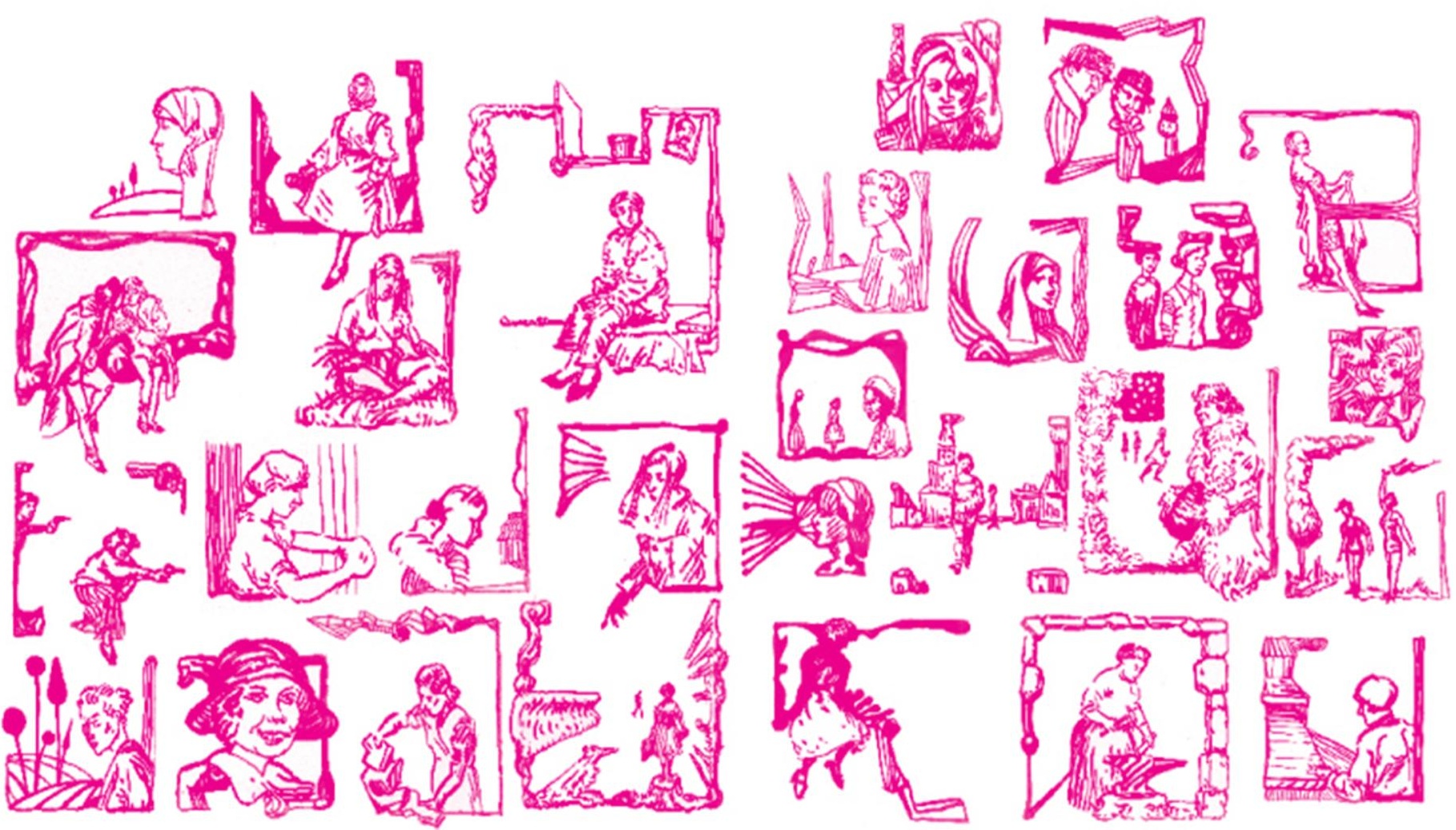




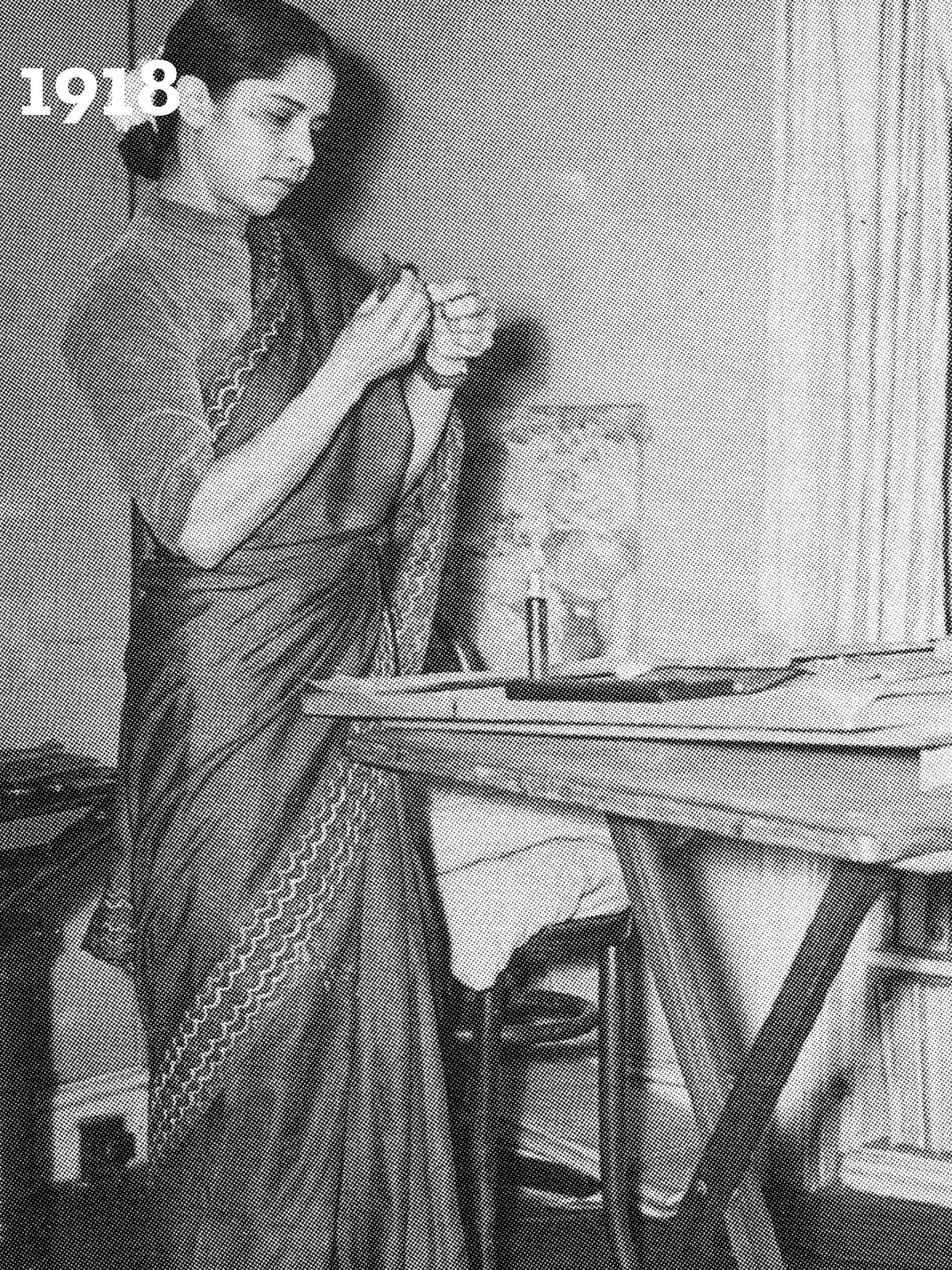




\section{Minnette de Silva}

A arquitecta do Sri Lanka

Nota biográfica:

Minnette de Silva nasceu em 1918, em Kandy, no Ceilão. Depois de iniciar os seus estudos de arquitectura em Bombaim inscreveu-se, em 1945, na Architectural Association, em Londres. Em 1947 participou no c I A m, em Bridgwater, onde conheceu Le Corbusier. Em 1948 foi aceite como membro do R I B A (Royal Institute of British Architects), a primeira mulher asiática. A sua primeira casa em Kandy (1947-5I), estabelecia um equilíbrio entre os conceitos modernistas e as necessidades da arquitectura tropical, que marcou a sua obra. Minnette de Silva morreu em I998, no Sri Lanka.

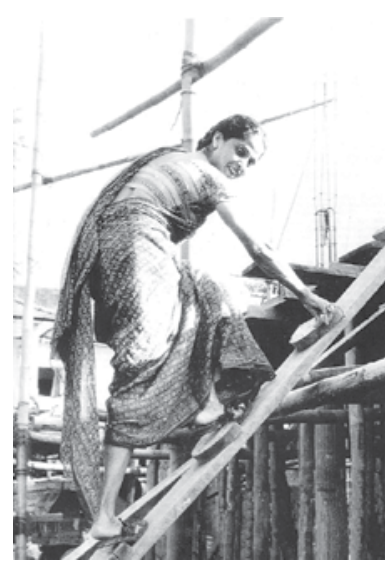



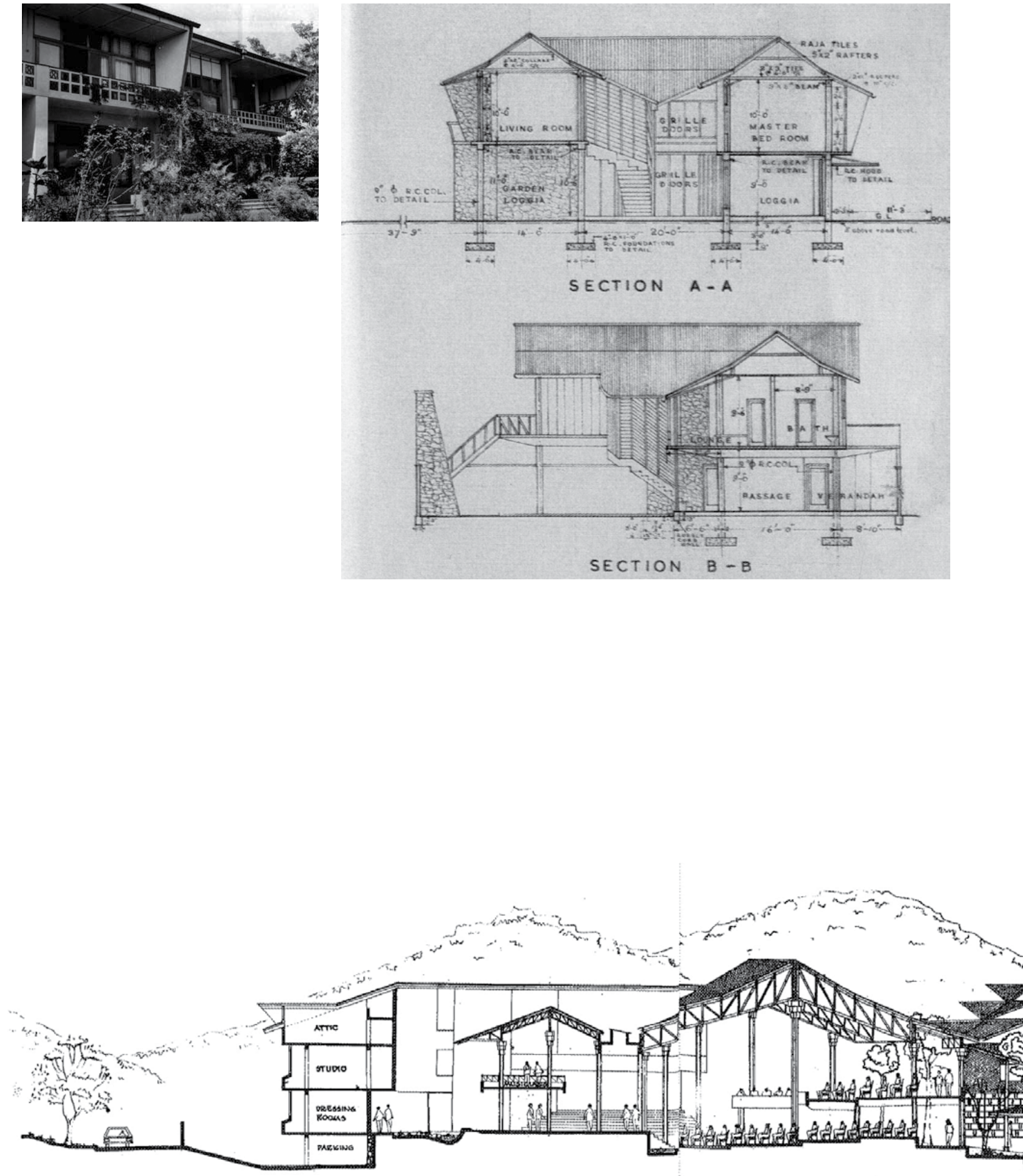
Perfil:

Minnette de Silva nasceu numa família da elite do Ceilão. Depois de Bombaim, a passagem pela Architectural Association em Londres, levam-na a participar mais activamente no mundo da arquitectura. Ainda estudante participa no c I A м de Bridgwater, em 1947, onde conhece Le Corbusier que marcaria a sua formação e futuro. Em I948 regressa ao Sri Lanka, com o intuito de contribuir para o aprofundamento da arquitectura local com os conhecimentos adquiridos na Europa. A sua obra vai ser assim uma articulação entre as referências da arquitectura moderna e os valores locais. A Casa Karunaratne, em Kandy, é prova desses princípios, e da confiança que lhe foi depositada pela sua família. A procura de conforto e de adequação levavam Minnette de Silva a considerar que os artistas, artesãos e arquitectos deviam projectar a casa em conjunto, utilizando elementos como tapetes, murais e objectos artesanais para tornar os espaços mais familiares e acolhedores. Mantinha-se fiel a elementos tradicionais, utilizava a justaposição de diferentes materiais, introduzindo elementos espaciais da arquitectura moderna. A utilização de materiais locais permitia-lhe reduzir os custos da habitação e ainda garantir uma melhor integração no ambiente envolvente. Minnette de Silva representou uma viragem na história da arquitectura tanto pelo facto de ser a primeira mulher arquitecta do Sri Lanka, bem como pela capacidade de adaptação das premissas modernistas a um ambiente e necessidades específicos. Assim, apesar do desconhecimento geral em relação à sua vida e obra, é de reconhecer o seu pioneirismo e singularidade. Das suas casas, seis na Índia, três no Bangladesh e três no Sri Lanka foram consideradas património da UnESCO. A sua obra é descrita como "regionalismo tropical". Reuniu em diversas viagens que realizou uma extensa documentação sobre a arquitectura indígena da Ásia, compilada em vários artigos e livros. Minnette de Silva considerava-se uma "mulher asiática arquitecta".
Fontes das imagens:

"A female maverick", (book review) Brittain-Catlin, Timothy; World of interiors 2000 Mar., v.20, n.3, pág. 31-32

$-$

"Minnette de Silva: Pioneer of modern architecture in Sri Lanka" Dissanayake, E., Orientations (Hong Kong), Vol. 13, N. ${ }^{8} 8$ (Agosto 1982), pág. 40-51. 17 ILLUS.

"Minnette de Silva: Pioneer of modern architecture in Sri Lanka" Dissanayake, E., Orientations (Hong Kong), Vol. 13, N. ${ }^{\circ} 8$ (Agosto 1982), pág. 40-51. 17 ILLUS.

"Minnette de Silva: Pioneer of modern architecture in Sri Lanka" Dissanayake, E., Orientations (Hong Kong), Vol. 13, N. ${ }^{\circ} 8$ (Agosto 1982), pág. 40-51. 17 ILLUS.

"Kandyan Art Association Centenary Center" Silva, Minnette de Silva, Mimar: architecture in development 1987 Mar. n. ${ }^{\circ} 23$, pág 32-36

Elementos do grupo: Joana Navarro Paula Monteiro Sara Monsanto Tânia Antunes Tânia Santos 